\title{
Commitment and its Relatedness to the Tendency towards Dimensions of Athletic Excellence at the Players of the Teams of the University of Mosul
}

\author{
Dr. Nagham Khalid Najeeb* \\ Research, Assistant professor, Iraq
}

*Corresponding Author: Dr. Nagham Khalid Najeeb, Research, Assistant professor, Iraq

\begin{abstract}
This research seeks to recognize the degree of commitment at players of the teams of the colleges of the university of Mosul and their tendency towards excellence, then to find the relation between the degree of commitment and the tendency towards athletic excellence of the players. Players interact with each other in the same team and usually face different situations, training difficulties and competition with rival teams, let alone other problems rising from life stress represented here by studying burdens. The player also bears the responsibility of representing sport teams of colleges of the university and he/she is obliged to give his/her best in competitions to reach excellence. The researcher decided to check the implementation of the two criteria on the players of the teams of colleges of the university of Mosul to know the degree of commitment and its relatedness to dimensions of athletic excellence; we seek to recognize the degree of commitment and the tendency to athletic excellence, and the possibility to study them in a scientific research by implementing the descriptive approach with surveying method on the 155 players of the teams of the colleges of Mosul university for the study year (2018-2019), representing teams of (football, futsal and $3 * 3$ basketball). The specimen first contained 120 players, then 15 players were excluded for exploration test and finally the specimen was reduced to 20 players. The researcher reached the results via using the statistical program (Spss) for the suitability of the two criteria of commitment and tendency towards excellence at the players of the colleges of Mosul university and found that their commitment was of low degree and their tendency towards excellence is high and this is a negative indication that affect their achievements level. There is a non-moral association between the criteria of commitment and that of tendency to excellence at the players of the colleges of Mosul university.
\end{abstract}

Keywords: Commitment, Tendency towards athletic excellence, players of teams of colleges of Mosul university

\section{INTRODUCTION AND IMPORTANCE OF THE RESEARCH}

The development in different fields of sport is a result of researches, studies and various sciences; generation physically healthy, psychologically sound and mentally mature who use science as an asset are the ones capable of making all dimensions of progressive development for their countries, and commitment is considered one important case in humans life, especially nowadays, as it is in the center of life organization and around it revolve the attitude of individuals and communities. Commitment is a positive feeling in its utmost intensity; it comes to unite with the community and adhering to it, committing to something whether it was a thought, a person or a belief means affiliation to it (Hamid and others, 2013, 230).

In the athletic education field, there is neither achievement nor athletic excellence for the teams of Mosul university's colleges without commitment, it represents the parameters that define the behavior of the athlete and his discipline in training, it also demonstrates his commitment to athletic activities, his feeling of responsibility, and his performing of athletic tasks. Hence, we find that getting the player to his best performance is connected to his good setting and preparation for sport competitions through athletic excellence which requires his possessing of a number of prerequisite qualities and abilities. The importance of the research, thus, lies in knowing the degree of commitment and its relatedness to dimensions of athletic excellence for the players of Mosul university's colleges, the thing that contributes to scientific enrichment for the researchers interested in this subject, where it can be used as a frame to resort to in performing future researches on different specimens. 


\subsection{The Community and Specimen of the Research}

The researcher defined the community of the research as the 155 players of the teams of the university of Mosul, representing (football, futsal and $3 * 3$ basketball), the research specimen was 120 players, 15 players were excluded as exploratory test, then the final specimen for the research was set to 20 players.

\section{FIELD PROCEDURES OF THE TEST}

\subsection{Instruments of the Research}

\subsubsection{Commitment Criterion}

The researcher used social commitment criterion prepared by (Al Khattab, 2006) and implemented on the teams of Mosul university by (Hamid and others, 2013), then adjusted it to suit the research specimen; the criterion consisted of 18 paragraphs and the answers were to be made by choosing one of three alternatives (yes, neutral, no). At the check of answers, the (yes) was to be granted three marks, the (neutral) to be granted two marks, whereas the (no) was to be granted one mark only. The maximum overall mark for the criterion is (54), whereas the minimum overall mark is (18). Annex (1)

\subsection{Credibility of the Criterion}

The researcher checked the credibility of the criterion via apparent credibility.

\subsubsection{Apparent Credibility of the Criterion}

It is a type of credibility which means "the extent of representation by the test to the content to be checked" (Al Assaf, 1995, 43-44), the researcher presented the paragraphs of the questionnaire to experts, and specialized personnel ${ }^{1}$ in sport psychology for evaluation and validity check, and to achieve the apparent credibility for the tests which is a kind of content credibility; the questionnaire gained (80\%) agreement by those personnel.

\subsubsection{The Exploratory Test}

An exploratory test was performed on a 3 players specimen chosen from the research specimen and the aim was:

- To check the suitability of the paragraphs set for this purpose.

- To check the clarity of the paragraphs to the examinee.

\subsubsection{Structural Credibility (Statistical Analysis of the Paragraphs)}

The following is a description of the methods of statistical analysis used to check the distinction credibility of the criterion.

\section{- The Method of Two Extreme Groups}

To find the distinction power and the internal coordination factor of the 18 criterion's paragraphs, the answers of the 120 players were analyzed and the aim of this procedure was to perform the statistical analysis for the paragraphs, as the criterion was adjusted to suit the specimen based on its distinction power and its coordination factor. The preliminary specimen consisted of 120 players, after the preparation of the instructions of the criterion, it was implemented on the distinction specimen; two extreme groups were taken after putting their marks in a descending order and to achieve that, (27\%) of the (highest and lowest)marks were chosen to represent the two extreme groups and the T- test

${ }^{1}$ Prof. UklahSulaiman Al Hory/Sport psychology/ College of basic education/ University of Mosul

Asst. Prof. WaleedThannoonYounis/ Sport psychology/College of physical education and sport sciences/ University of Mosul

Asst. Prof. Rafi'aIdreesAbdulghafoor/ Sport psychology/ College of physical education and sport sciences/ University of Mosul

Asst. Prof. ThamerMahmoodThannon/ Sport psychology/ Sport psychology/ College of basic education/ University of Mosul

Instructor.MahmoodMutar Ali/ Sport psychology/ College of physical education and sport sciences/ University of Mosul 
Commitment and its Relatedness to the Tendency towards Dimensions of Athletic Excellence at the Players of the Teams of the University of Mosul

value calculated to test the significance of variation among the averages of the answers of the two groups for each paragraph, table (1) demonstrates that

Table1: Illustrates the distinction power by the two extreme groups' method for the paragraphs of psychological empowerment criterion

\begin{tabular}{|c|c|c|c|c|c|c|c|}
\hline \multirow{2}{*}{$\begin{array}{c}\text { Paragraph } \\
\text { No. }\end{array}$} & \multicolumn{2}{|c|}{ Upper group } & \multicolumn{2}{|c|}{ Lower group } & \multirow{2}{*}{$\begin{array}{l}\text { Calculated } \\
\text { T- Value }\end{array}$} & \multirow{2}{*}{$\begin{array}{l}\text { (Sig) } \\
\text { value }\end{array}$} & \multirow{2}{*}{$\begin{array}{c}\text { Distinction } \\
\text { Power of the } \\
\text { Paragraph }\end{array}$} \\
\hline & $\mathbf{X}$ & $\mathbf{Y}$ & $\mathbf{X}$ & $\mathbf{y}$ & & & \\
\hline 1 & 2.566 & 0.499 & 2.216 & 0.751 & 3.107 & 0.002 & Distinct \\
\hline 2 & 2.583 & 0.497 & 2.316 & 0.596 & 2.660 & 0.009 & Distinct \\
\hline 3 & 2.266 & 0.634 & 2.00 & 0.736 & 2.125 & 0.036 & Distinct \\
\hline 4 & 2.533 & 0.595 & 2.050 & 0.622 & 4.346 & 0.00 & Distinct \\
\hline 5 & 2.4 & 0.668 & 2.066 & 0.685 & 2.696 & 0.008 & Distinct \\
\hline 6 & 2.433 & 0.62 & 1.983 & 0.676 & 3.797 & 0.00 & Distinct \\
\hline 7 & 2.666 & 0.475 & 2.266 & 0.606 & 4.019 & 0.00 & Distinct \\
\hline 8 & 2.433 & 0.563 & 2.166 & 0.668 & 2.363 & 0.020 & Distinct \\
\hline 9 & 2.316 & 0.596 & 1.966 & 0.662 & 3.040 & 0.003 & Distinct \\
\hline 10 & 2.55 & 0.501 & 2.15 & 0.708 & 3.568 & 0.001 & Distinct \\
\hline 11 & 2.633 & 0.485 & 2.216 & 0.666 & 3.914 & 0.000 & Distinct \\
\hline 12 & 2.483 & 0.65 & 2.15 & 0.708 & 2.683 & 0.008 & Distinct \\
\hline 13 & 2.4 & 0.693 & 2.133 & 0.675 & 2.133 & 0.035 & Distinct \\
\hline 14 & 2.616 & 0.49 & 2.3 & 0.645 & 3.025 & 0.003 & Distinct \\
\hline 15 & 2.532 & 0.503 & 2.15 & 0.684 & 3.495 & 0.001 & Distinct \\
\hline 16 & 2.566 & 0.563 & 2.25 & 0.627 & 2.908 & 0.004 & Distinct \\
\hline 17 & 2.6 & 0.527 & 2.133 & 0.675 & 4.218 & 0.00 & Distinct \\
\hline 18 & 2.483 & 0.567 & 2.183 & 0.676 & 2.633 & 0.01 & Distinct \\
\hline
\end{tabular}

From the above table we note that the T- values of the criterion's paragraphs varied between $(2.125$ 4.346), when compared to the tabular $T$ - value of (1.984) against freedom degree of (118) and morality level of (0.05) and in light of that we note that (18) paragraphs showed a distinction capacity concluded from comparing the calculated T-value with its tabular value, and since the calculated Tvalue was more than the tabular one, none of the paragraphs was excluded since there was none with low distinction.

\section{- Internal Coordination Factor Method}

"The test of the internal coordination factor or its congruity factor leads to obtaining an estimation of its structural credibility" (Bahy and Al Azhary, 2006, 125), the factor of association of each paragraph's mark to the overall mark of the criterion for the same specimen of (120) players, and it is called the credibility of the criterion's internal coordination, the simple association factor (Person ) was used to this aim as follows:

Table2: Illustrates the factor of association between the paragraph and the overall markof the criterion of psychological empowerment

\begin{tabular}{|l|l|l|l|l|l|}
\hline Paragraph & $\begin{array}{c}\text { Factor of } \\
\text { association }\end{array}$ & (Sig) Value & Paragraph & $\begin{array}{c}\text { Factor of } \\
\text { association }\end{array}$ & (Sig) Value \\
\hline 1 & $* * 0.323$ & 0.00 & 10 & $* * 0.368$ & 0.000 \\
\hline 2 & $* * 0.232$ & 0.011 & 11 & $* * 0.434$ & 0.000 \\
\hline 3 & $* * 0.339$ & 0.000 & 12 & $* * 0.443$ & 0.000 \\
\hline 4 & $* * 0.427$ & 0.000 & 13 & $* * 0.213$ & 0.019 \\
\hline 5 & $* * 0.260$ & 0.000 & 14 & $* * 0.291$ & 0.001 \\
\hline 6 & $* * 0.382$ & 0.000 & 15 & $* * 0.406$ & 0.000 \\
\hline 7 & $* * 0.368$ & 0.000 & 16 & $* * 0.265$ & 0.003 \\
\hline 8 & $* * 0.373$ & 0.003 & 17 & $* * 0.476$ & 0.000 \\
\hline 9 & $* * 0.389$ & 0.000 & 18 & $* * 0.238$ & 0.009 \\
\hline
\end{tabular}

The tabular value of the association factor of freedom degree $(118)$ and a significance level $(0.005)=(0.217)$

From table (2) it is evident that the values of association factor between the paragraphs of the criterion and the overall mark of the criterion approached (0.213- 0.476), and when we refer to the tables of the significance of the association factor at (118) degree of freedom and morality level of (0.05), we find 
that the tabular $(\mathrm{R})$ value equals $(0.194)$ when compared to the calculated $(\mathrm{R})$ value of the association factors of the paragraphs, we find all the paragraphs of the criterion were distinct.

\subsection{Stability of the Criterion}

The instrument is considered stable when it gives the same results in its measurement of the same phenomenon many times, and to obtain the stability of the criterion, the researcher distributed the test on (35) players specimen as a preliminary test, then the same test was repeated after 10 days

\subsubsection{Criterion of Tendency Towards Dimensions of Athletic Excellence}

The researcher used the criterion of tendency towards the dimensions of athletic excellence designed by Donald Dell then translated into Arabic by (Alawi, 1998). The criterion consists of (54) paragraphs and contains (3) dimensions; (tendency towards self discipline, tendency towards feeling, tendency towards respecting others), and each paragraph of the criterion is opposed by five alternatives; (highly agree, agree, uncertain, donot agree, highly donot agree). The phrases of each dimension is checked separately and marks were estimated for the criterion $(5,4,3,2,1)$ marks for the positive paragraphs according to the alternatives for the positive paragraphs and the marks $(1,2,3,4,5)$ marks for the negative paragraphs according to the alternatives of the negative paragraphs. Accordingly, if the lowest mark reached (54) and the highest mark of the criterion reached (270). (Alawi, 1998, 208).

\subsubsection{Credibility of the Criterion}

The researcher checked the credibility of the criterion by apparent credibility.

\subsubsection{Apparent Credibility of the Criterion}

The researcher checked the credibility of the criterion by using apparent credibility which is the suitability of the criterion to its purpose like the clarity of its instructions and the validity of its phrases; the criterion was presented to a number of experts, mentioned earlier, specialized in sport psychology to evaluate it and judge its validity to achieve the apparent credibility of the tests (which is a kind of content credibility), and obtained (80\%) agreement of the experts.

\subsection{Statistical Means}

Statistical processing was performed using the computer and the (SPSS) system.

\section{Presentation AND discussion OF The ReSUlts}

\subsection{Presentation of Results}

Table3: Illustrates the arithmetic means, the standard deviation, the mode and the skewness factor of the answers of the research specimen for the criterion of commitment and the tendency towards athletic excellence.

\begin{tabular}{|c|c|c|c|c|c|}
\hline $\begin{array}{c}\text { Statistical indexes } \\
\text { Criterion }\end{array}$ & $\begin{array}{c}\text { Number of the } \\
\text { specimen }\end{array}$ & $\begin{array}{c}\text { Arithmetic } \\
\text { means }\end{array}$ & $\begin{array}{c}\text { Standard } \\
\text { deviation }\end{array}$ & Mode & $\begin{array}{c}\text { Skewness } \\
\text { factor }\end{array}$ \\
\hline Commitment & 20 & 24.850 & 5.264 & 21 & -0.730 \\
\cline { 1 - 5 } $\begin{array}{c}\text { Tendency towards } \\
\text { the dimensions of } \\
\text { athletic excellence }\end{array}$ & & 183.75 & 17.778 & 200 & 0.914 \\
\hline
\end{tabular}

Table4: Illustrates the arithmetic means, the standard deviation, the assumption means, the T-value and the (sig) value for the specimen of the criteria of commitment and tendency towards the dimensions of athletic excellence.

\begin{tabular}{|c|c|c|c|c|c|c|}
\hline $\begin{array}{c}\text { Statistical indexes } \\
\text { Criterion }\end{array}$ & Specimen & $\begin{array}{c}\text { Arithmetic } \\
\text { means }\end{array}$ & $\begin{array}{c}\text { Standard } \\
\text { deviation }\end{array}$ & $\begin{array}{c}\text { Assumption } \\
\text { means }\end{array}$ & $\begin{array}{c}\text { Calculated } \\
\text { T- value }\end{array}$ & $\begin{array}{c}\text { (Sig) } \\
\text { value }\end{array}$ \\
\hline Commitment & 20 & 24.850 & 5.264 & 36 & -9.472 & 0.000 \\
\cline { 1 - 6 } $\begin{array}{c}\text { Tendency towards } \\
\text { the dimensions of } \\
\text { athletic excellence }\end{array}$ & & 183.75 & 17.778 & 162 & 5.471 & 0.00 \\
\cline { 3 - 7 }
\end{tabular}

Table5: Illustrating simple association (Person's) between the overall degree of the criteria of commitment and of tendency towards dimensions of athletic excellence of the research specimen.

\begin{tabular}{|c|c|c|c|}
\hline $\begin{array}{c}\text { Statistical indexes } \\
\text { Criterion }\end{array}$ & Specimen & Calculated (R) value & (Sig) value \\
\hline
\end{tabular}


Commitment and its Relatedness to the Tendency towards Dimensions of Athletic Excellence at the Players of the Teams of the University of Mosul

\begin{tabular}{|c|c|c|c|}
\hline Commitment & 20 & -0.154 & 0.517 \\
$\begin{array}{c}\text { Tendency towards the } \\
\text { dimensions of athletic } \\
\text { excellence }\end{array}$ & & & \\
\hline
\end{tabular}

* Moral at (0.05) level

\subsection{Interpretation of Results}

From table (3) we note that the values of skewness factor of the two criteria indicate the suitability of the two criteria for the specimen as the skewness factor falls between $(+/-1)$, whereas the values of the arithmetic means for the answers of the specimen regarding the criterion of commitment was lower than the assumption means, and this signifies that the players have a low level of commitment, as regarding the criterion of tendency towards the dimensions of athletic excellence, the arithmetic means values of the specimen's answers were more than the assumption means of the criterion and this indicates that the players have a high level of tendency towards the dimension of athletic excellence. From table (5) we note that the value of probability is smaller than the morality level (0.05), the thing that indicates that there is no strong moral relation between the two criteria; the researcher ascribed theses results to a number of reasons: the lack of sufficient time for the players to devote for training and participation in competitions, to achieve the aspired results, being students in scientific or humanitarian colleges and have their commitments to lectures, the researcher also mentioned the absence of scheduled sport education lectures, not to mentioned that the purpose of those players of the university is entertainment and participation, to mitigate the burdens of studying in their colleges not to compete, and this is in line with (Dodo, 2013) that the athletic excellence comes from the persistence of the player in training and exerting the utmost efforts to appear in a good shape and to achieve the best results. The emotional experiences related to sport competitions like success and failure or defeat, are considered the most important motivations for the athletic excellence as well as the social and individual tendencies.

\section{CONCLUSiOnS}

In light of results' presentation, analysis and discussion, the researcher concluded the following:

- The criteria of commitment and tendency towards the dimensions of athletic excellence are suitable to the players of Mosul university's colleges.

- The players of Mosul university colleges' teams have low level of commitment but high level of tendency towards the dimensions of athletic excellence, the thing that signifies a negative result and this will affect the level of achievement for these players.

- There are non- moral relatedness between the criteria of commitment and that of the tendency towards the dimensions of athletic excellence at the players of Mosul university.

\section{RECOMMENDATIONS}

The researcher recommends the following:

- To pay attention to the sport activities in the colleges of Mosul university to raise the level of commitment in practicing the different sport activities for the students.

- The necessity of supporting sport activities by officials of the colleges represented by the deans and their deputies to achieve commitment when participating in sport activities to fulfill the dimensions of athletic excellence.

\section{REFERENCES}

[1] Bahy, Mustafa Husain and Al Azhary, Muna Ahmad (2006): "Evaluation Instruments in Scientific Research (Design and Construction), First Edition, Anglo- Egyptian Library, Cairo

[2] Hamid, Abdullah Majid and others (2013): "Classification of the Degree of Social Commitment at the players of the Teams of Mosul University, the Magazine of Basic Education College, issue 13, Babel University. 
Commitment and its Relatedness to the Tendency towards Dimensions of Athletic Excellence at the Players of the Teams of the University of Mosul

[3] Dodo, Balqasim (2013): "Analytic study of the Trends of Athletic Excellenceat the Participants in the National Championship for Schools- Collective Games- and their Relation to Some Factors", Human and Social Sciences Magazine, issue 10, Algeria.

[4] Al Assaf, Salih Bin Hamad (1995): " Entrance to Behavioral Sciences Research", Al'Ubaikan Library, $1^{\text {st }}$ floor, Riyadh, Saudi Arabia

[5] Alawi, Mohammad Hasan (1998): " Encyclopedia of Psychological Tests for Athletes", Al Kitab publication center, floor (1), Cairo

Citation: Dr. Nagham Khalid Najeeb. "Commitment and its Relatedness to the Tendency towards Dimensions of Athletic Excellence at the Players of the Teams of the University of Mosul" International Journal of Sports and Physical Education (IJSPE), vol 5, no. 3, 2019, pp. 13-18. doi: http://dx.doi.org/10.204 31/2454-6380.0503003.

Copyright: (C) 2019 Authors. This is an open-access article distributed under the terms of the Creative Commons Attribution License, which permits unrestricted use, distribution, and reproduction in any medium, provided the original author and source are credited. 